\title{
Density Functional Theory Studies on Sulfur-Polyacrylonitrile as a Cathode Host Material for Lithium-Sulfur Batteries
}

\author{
Samuel Bertolini and Timo Jacob*
}

Cite This: ACS Omega 2021, 6, 9700-9708

Read Online

ABSTRACT: Cyclized polyacrylonitrile, which can be obtained by vulcanization of polyacrylonitrile with sulfur, is an electronconductive polymer that can be used as a host material in lithium-sulfur batteries. Using density functional theory, we investigated the interaction between a surrounding electrolyte and the polymeric sulfur-polyacrylonitrile (SPAN) electrode. In particular, we focused on different configurations, where the system contains 1,3-dioxane as a solvent and can have (i) polysulfide (PS) solvated in the electrolyte, (ii) a PS attached to the polymer backbone, (iii) lithium bis(trifluoromethanesulfonyl)imide (LiTF-

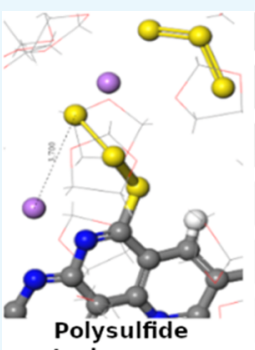
capturing process

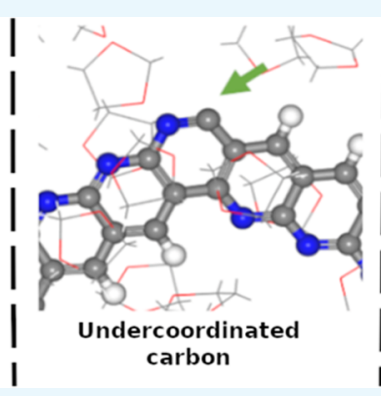
carbon

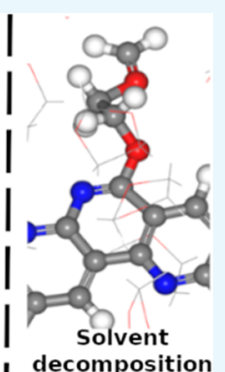

decomposition SI) as a salt dissolved in the electrolyte, and (iv) both PS and LiTFSI dissolved in the electrolyte. We found that the polymer, when having a hydrogen vacancy at a carbon atom (undercoordinated carbon) of the polymer backbone, is able to not only capture a PS from the electrolyte but also decompose and bind to the solvent and/or remove lithium from the PS. During this capturing process, the polysulfide might undergo S-S bond cleavage and recombination, accompanied by a charge transfer between the polysulfide and polymer. Thus, cyclized polyacrylonitrile not only is an interesting host material but also acts as an active material, together with sulfur, by capturing Li from the polysulfide.

\section{INTRODUCTION}

Lithium batteries are used for energy storage in different devices, such as cellphones and electric vehicles, and many other applications, both stationary and portable. ${ }^{1-6}$ However, the current specific capacity $\left(150 \mathrm{Wh} \cdot \mathrm{kg}^{-1}\right)$ of Li-ion batteries needs to be augmented to supply the increasing demands, for instance in electric vehicles. ${ }^{7,8}$ Here, lithium-sulfur batteries (LiSBs) are promising future candidates due to their high theoretical specific capacity of $2567 \mathrm{Wh} \cdot \mathrm{kg}^{-1}$, low toxicity, and low cost of the graphite/sulfur cathode. ${ }^{9-13}$ However, LiSBs have some challenges that still have to be overcome, such as blockage of the active material in the cathode, the formation of isolator layers for electron passage, volumetric expansion, and the so-called polysulfide (PS) shuttle. ${ }^{14-16}$ During cycling of LiSBs, long-chain polysulfides $\left(\mathrm{Li}_{2} \mathrm{~S}_{x}, 3 \leq x \leq 8\right)$ can dissolve into and shuttle through the electrolyte, facilitating degradation of the anode and self-discharge. ${ }^{17-20}$

Since sulfur is a nonconductive material, graphite is usually used as a host material in LiSBs, providing the necessary electronic conductivity. Many strategies to reduce the degradation and fading cyclability of LiSBs, which is promoted by the migration of the PS to the anode, are based on changing the architecture of this graphite, for instance, by using carbon nanotubes, micropores, hollow carbon spheres, or by encapsulating sulfur inside a polymer as a yolk, where the polymer shell allows Li-ion transportation. ${ }^{21-37}$ Additives to the host material are also used to force the dissolved polysulfides to adsorb again into the electrolyte, such as magnesium oxide particles added to the graphite. ${ }^{38-42}$ The graphite can also be modified by doping, e.g., with nitrogen, to chemisorb the PSs. ${ }^{43-45}$ Other attempts have tried to reduce the PS shuttle effects by using membranes that decrease the amount of PSs reaching the anode or insertion of an additive to the electrolyte to actively engineer the solid-electrolyte interphase (SEI) at the anode, finally protecting the system against PS degradation. ${ }^{46}$ The SEI can also be produced at the cathode by the attack of some salts (e.g., LiBr) on the electrolyte, leading to an SEI at the cathode that reduces PS migration. $^{47-50}$

Alternative materials to graphite as host materials in LiSBs that also improve the cycling performance are polymer-sulfur composites, of which polyacrylonitrile (PAN) is an interesting candidate for the cathode side. ${ }^{51-56}$ Vulcanization of PAN with sulfur leads to cyclization of the PAN polymer, producing $\pi$ conjugated motifs as well as sulfur chains that are chemically bound to $\mathrm{C}$ atoms of the PAN polymer. ${ }^{57-59}$ During PAN synthesis, it is possible to observe a reduction of the hydrogen content and, at the same time, the formation of hydrogen

Received: January 18, 2021

Accepted: March 15, 2021

Published: March 31, 2021 

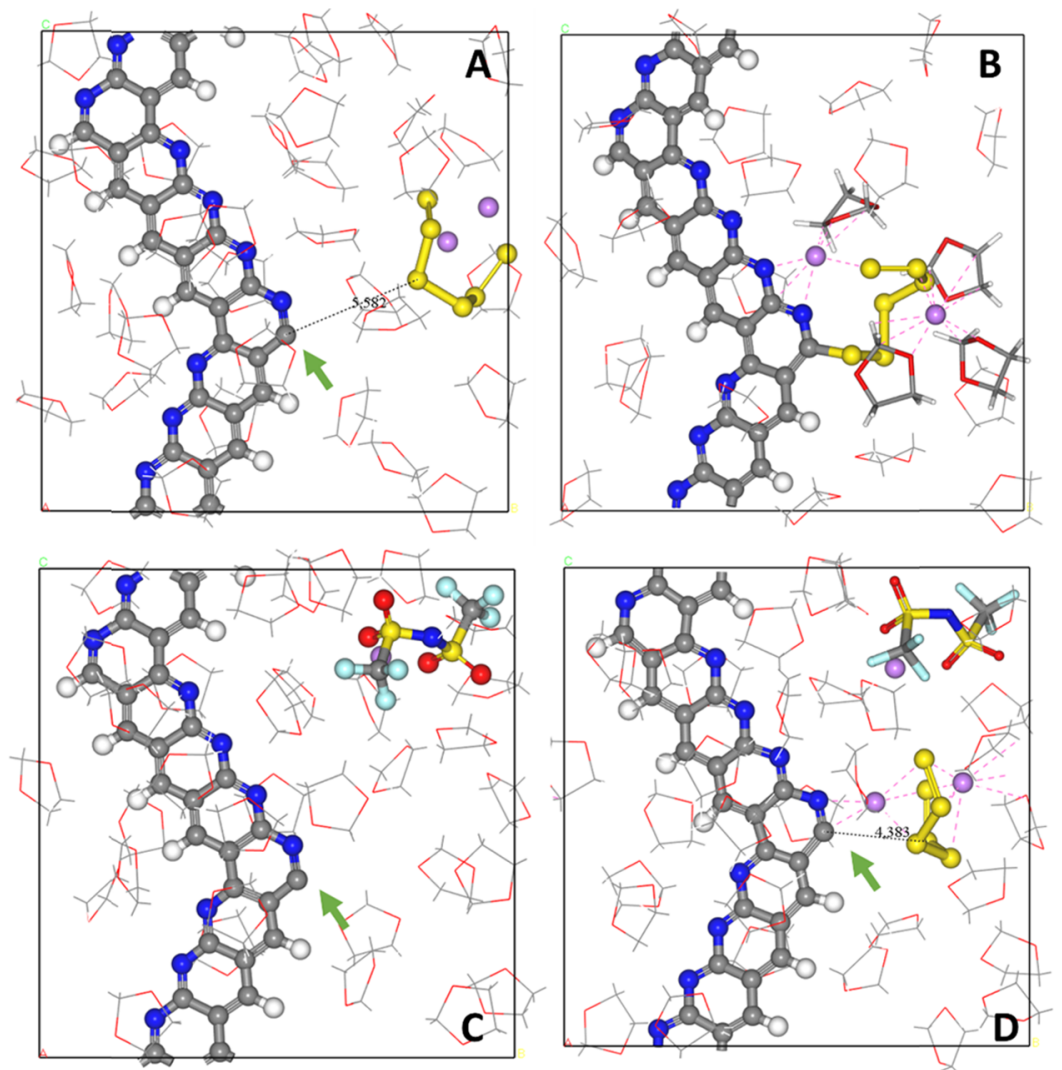

Figure 1. Initial structure models used to investigate the interactions between PS and LiTFSI with a single site of c-PAN. (A) Single $C_{u c}$ surrounded by a PS-containing electrolyte. (B) Site in c-PAN which is considered initially occupied by PS. (C) Single $\mathrm{C}_{\mathrm{uc}}$ surrounded by a LiTFSIcontaining electrolyte. (D) Single $\mathrm{C}_{\mathrm{uc}}$ surrounded by an electrolyte containing both LiTFSI and PS. Color coding: hydrogen (white), lithium (purple), carbon (gray), nitrogen (blue), oxygen (red), fluorine (cyan), and sulfur (yellow). Green arrows point to a carbon with a missing hydrogen, representing a $\mathrm{C}_{\mathrm{uc}}$.

sulfides and $\mathrm{N}-\mathrm{C}-\mathrm{S}$ units, indicating the formation of 2pyridylthiolates and thioamides. ${ }^{57,60}$ After this synthesis, the polymeric structure contains $\pi$-conjugated units, enabling the usual identification as cyclized polyacrylonitrile (c-PAN). Regarding its use in batteries, the performance of this polymer as the host material is affected by the temperature of sulfurpolyacrylonitrile (SPAN) vulcanization, the sulfur content, and the solvent composition, indicating that the synthesis process strongly affects the behavior of the LiSB. Chen et al. suggested that dehydrogenation of PAN first creates the cyclized structure (c-PAN) and then produces uncoordinated carbons on the c-PAN backbone. ${ }^{61}$ Moreover, Archer et al. ${ }^{62}$ observed oscillations in the number of $\mathrm{C}-\mathrm{S}$ bonds during cycling, which was interpreted as a rupture process between the polymer and the sulfur chain during lithiation.

In this work, we have used density functional theory (DFT) to resolve the structure of sulfur-polyacrylonitrile ${ }^{58,59}$ and to investigate the PS shuttle effect in the anode as well as graphite cathodes. ${ }^{63-70}$ We further considered the situation that sulfur binds to an undercoordinated carbon such as in c-PAN. Here, we used $a b$ initio molecular dynamics (AIMD) to study the interaction of the host material with a polysulfide-containing electrolyte. AIMD is commonly applied for investigation on LiSB (using a time scale of picoseconds), due to its high accuracy, both to describe electron distribution and to supply energy to overpass the active barrier in a reaction. In contrast, classical methods and static calculations are not able to provide these outcomes at the same time. ${ }^{71-74}$ AIMD can give insights into the behavior of the cathode, and the structure of adsorbed PSs and help answering the question of whether c-PAN is capable of capturing PSs from the electrolyte. As c-PAN as a host material shows a higher cyclability than graphite, one of our aims was to understand the possibility of chemisorption and incorporation of the PSs into the c-PAN network, as well as the role and influence of the electrolyte on this process.

\section{COMPUTATIONAL METHODS}

DFT calculations were performed with the Vienna $\mathrm{Ab}$ initio Simulation Package (VASP) ${ }^{75,76}$ employing plane-wave basis sets $^{77,78}$ with an energy cutoff of $400 \mathrm{eV}$, while electron-core interactions were described by projector-augmented wave (PAW) pseudopotentials. ${ }^{79,80}$ For integrations in the reciprocal space, the Brillouin zone was sampled with a Monkhorst-Pack mesh $^{81}$ of $2 \times 2 \times 2 k$-points. The electronic structure was relaxed until the energy was converged up to an energy change of $10^{-4} \mathrm{eV}$. Geometries were optimized using the conjugategradient (CG) approach with a force convergence criterion of $10^{-3} \mathrm{eV} / \AA$. Gaussian smearing with a width of $0.05 \mathrm{eV}$ was utilized. $\mathrm{Ab}$ initio molecular dynamics (AIMD) simulations were carried out in the canonical ensemble (NVT) at $330 \mathrm{~K}$ using time steps of $1 \mathrm{fs}$, while the Nosé thermostat was used to control temperature oscillations during the simulation with a Nosé mass parameter ${ }^{82-84}$ of 0.5 . Charge analyses were performed on the basis of Bader charges ${ }^{85}$ obtained with a denser reciprocal grid of $4 \times 4 \times 4 k$-points. Finally, in all studies, van der Waals (vdW) dispersion corrections were 


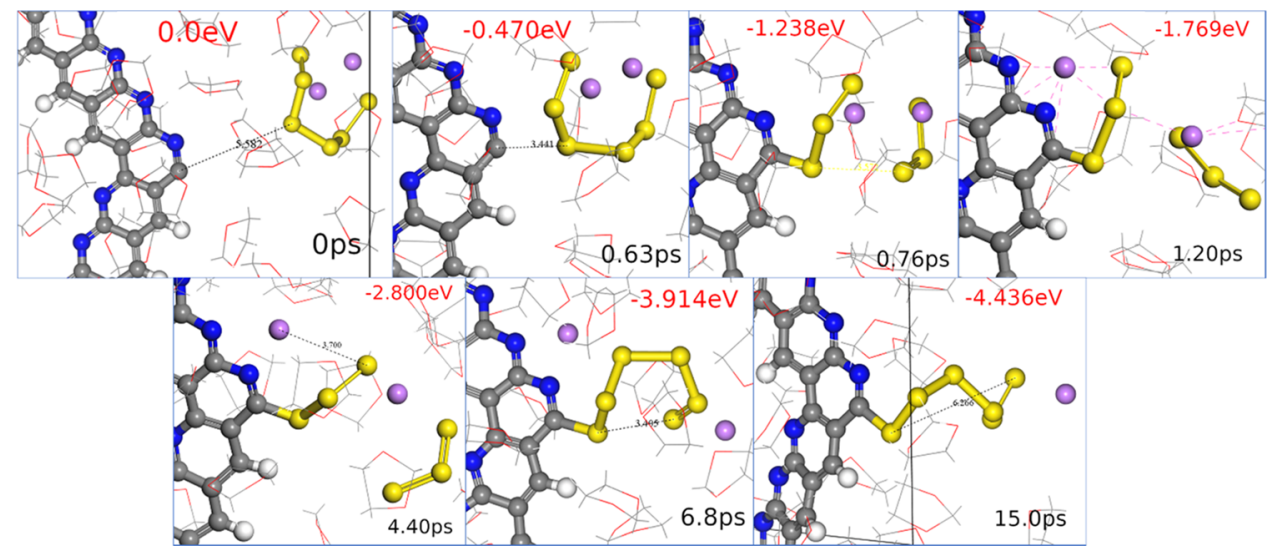

Figure 2. Screenshots along with the AIMD simulation showing the capturing of PS dissolved in the electrolyte by the c-PAN. The color code is as described in Figure 1.

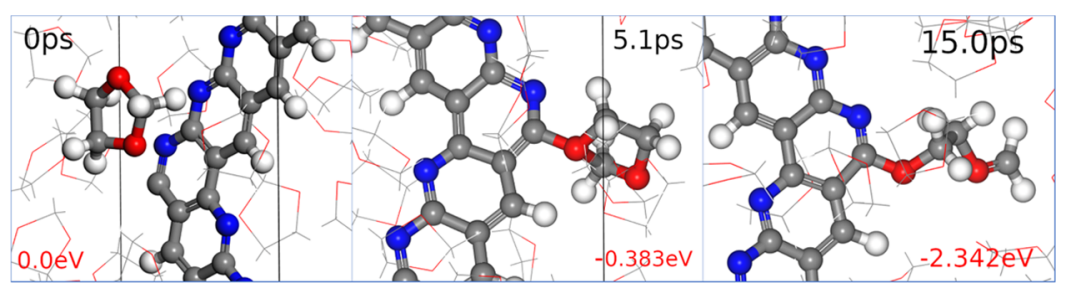

Figure 3. Decomposition mechanism of the solvent in the presence of a $\mathrm{C}_{\mathrm{uc}}$ of c-PAN. The color code is as described in Figure 1.

included by the DFT-D3 approximation in the Becke-Johnson formulation. ${ }^{86}$ To estimate individual bond strengths, the Crystal Orbital Hamilton Population (COHP) and Crystal Orbital Overlap Population (COOP) were calculated using the LOBSTER program. ${ }^{87,88}$ VESTA $^{89}$ software was used for visualization of the charge isosurface and visual molecular dynamics (VMD) ${ }^{90}$ was used for visualization of the molecular structures.

To build up the different systems, the electrolyte molecules were preoptimized individually using the Gaussian09 (G09) package $^{91}$ with the B3PW91 hybrid functional and a 6-311+ $+\mathrm{G}(\mathrm{p}, \mathrm{d})$ basis set, ${ }^{92,93}$ allowing a better initial configuration to run in periodic boundary conditions when using VASP. Afterward, the full system (i.e., c-PAN with electrolyte) was built such that the individual electrolyte molecules were first kept rigid in their preoptimized structures, while c-PAN was optimized based on the consistent-valence forcefield (CVFF). ${ }^{94}$ Finally, this provided the initial configurations for the subsequent AIMD simulations. This procedure allows saving computational resources and eliminating drifts in both energy and temperature at the beginning of the simulation.

As a solvent, we used 1,3-dioxolane (DOL) that contained one molecule of PS $\left(\mathrm{Li}_{2} \mathrm{~S}_{6}\right)$, for which the electrolyte density was set to be $1.06 \mathrm{~g} / \mathrm{cm}^{3}$. The literature indicates that in the PAN structure, sulfur chains of five and eight atoms $\left(\mathrm{S}_{x}, 5 \leq x\right.$ $\leq 8)$ are stable. ${ }^{58,59}$ Therefore, as a compromise for the present studies, we used polysulfides containing six sulfur atoms in the chain. All systems were studied in $15 \AA \times 18 \AA \times 18.5 \AA$ simulation boxes, where the polymer backbone was oriented along the $z$-direction.

Figure 1 summarizes the different initial configurations for our AIMD studies that were used to investigate the interaction between PS, the electrolyte, and c-PAN. Here we successively increased the complexity of the system. In the first two cases (Figure $1 \mathrm{~A}, \mathrm{~B})$, the interaction of the PS $\left(\mathrm{Li}_{2} \mathrm{~S}_{6}\right)$ with c-PAN was investigated by first considering the detached case (Figure 1A) and afterward binding the PS to one of the undercoordinated carbon atoms of the backbone (hereafter, this undercoordinated site is called $C_{u c}$; see Figure $1 \mathrm{~A}$ ). The $C_{u c}$ position was selected based on where the hydrogen in c-PAN is the most thermodynamically favorable to be removed. With the third and fourth systems, the role of the added salt lithium bis(trifluoromethanesulfonyl)imide (LiTFSI; Figure 1C) and finally the combined system where both PS and LiTFSI are in the simulation box were considered (see Figure 1D). The last two cases contain an undercoordinated carbon site, $\mathrm{C}_{\mathrm{uc}}$.

To highlight the different processes or reactions observed during the simulations, individual snapshots along the AIMD were selected. To further analyze the energetics between cPAN and PS, for each selected frame an additional subsequent energy minimization was performed in such a way that the cPAN and PS structures were kept fixed, while only the electrolyte molecules were geometrically optimized (see Figures 2 and 3, as well as Figures S1 and S2). This procedure provided direct insights into the energetics during the reaction processes between PS and c-PAN but reduced temperatureinduced fluctuation effects in the solvent.

\section{RESULTS AND DISCUSSION}

To study the interaction of PS and c-PAN, our simulation model systems were constructed such that a single hydrogen termination on the carbon backbone of the c-PAN host material was removed (see Figure 1). This is motivated by the experimental observations that vulcanization of PAN leads to the formation of conjugated $\pi$-units, the production of $\mathrm{H}_{2} \mathrm{~S}$, the formation of $\mathrm{C}-\mathrm{S}$ bonds, and the creation of uncoordinated carbon atoms at the c-PAN backbone. ${ }^{57-59,61,95}$ Moreover, since some salts can remove hydrogens from the solvent surrounding the cathode, ${ }^{47-50}$ there is also the possibility that those salts remove hydrogens from the SPAN 
backbone during cycling, producing an undercoordinated carbon on c-PAN. During cycling, lithium will react with the sulfur present in the SPAN and form a PS soluble in the electrolyte; thus, PS might also be present in the electrolyte. Therefore, we also investigated the interaction between c-PAN and an electrolyte molecule. Overall, the following different situations were considered: (1) an initially ringlike PS interacts with a $\mathrm{C}_{\mathrm{uc}}$ (i.e., missing $\mathrm{H}$-saturation) site of c-PAN; (2) this particular site of c-PAN remains unoccupied, i.e., there is a missing $\mathrm{H}$ atom in the backbone $\left(\mathrm{C}_{\mathrm{uc}}\right)$ and the electrolyte contains only DOL and LiTFSI; (3) the $\mathrm{C}_{\mathrm{uc}}$ site is in contact with the electrolyte that contains only DOL and a PS molecule being close to $(5.5 \AA)$ this $\mathrm{C}_{\mathrm{uc}}$ (thus has a strong tendency to interact); and finally, (4) the electrolyte contains the solvent, PS, LiTFSI, and a $\mathrm{C}_{\mathrm{uc}}$ on the c-PAN polymer. Additionally, we also positioned the LiTFSI closer to the $\mathrm{C}_{\mathrm{uc}}$ site (see Figure S3) to investigate possible reactions between the polymer backbone and the salt and at the same time reducing the possibility of $\mathrm{C}_{\mathrm{uc}}$ to react with the solvent.

In the model shown in Figure $1 \mathrm{~B}$, the PS has initially a ringlike structure connected to the c-PAN. During the simulation, the c-PAN receives a $\mathrm{Li}$ atom that was previously solvated by the PS. As observed in Figure $\mathrm{S} 1$, the $\mathrm{Li}$ atom migrates through the c-PAN, increasing its distance to the PS (from 2.8 to $5.4 \AA$ ). In the direct vicinity of the $\mathrm{Li}$ atom removed from the PS, there are $\mathrm{N}$ atoms from the c-PAN as well as $\mathrm{O}$ atoms from different solvent molecules that form the remaining solvation shell. Consequently, this $\mathrm{Li}$ has four nearest-neighbor atoms originating from different solvent molecules and c-PAN. Once Li is removed from the PS, the PS molecule elongates, i.e., the distance between $S$ in the edge of the PS and the $S$ atoms that form the connection to the polymer changes from 3.8 to 5.7 A (comparing initial and final structures). Also, the other $\mathrm{Li}$ atom remaining at the PS moves to the edge of the PS chain (not connected to the polymer), and the first solvation shell of this $\mathrm{Li}$ atom is surrounded by one $\mathrm{S}$ atom and $\mathrm{O}$ atoms from the surrounding solvent molecules. This indicates the capacity of the polymer to interact with Li not only as a host material for sulfur but also by consuming $\mathrm{Li}$, consequently acting as an active material during battery cycling. This behavior was also suggested by Wang et al. ${ }^{96}$ who argued on the absorption of $\mathrm{Li}$ ions by the polymer backbone.

When the PS is initially dissolved into the electrolyte, the $\mathrm{C}_{\mathrm{uc}}$ site of c-PAN is able to catch the PS molecule from the electrolyte (see Figure 2). During the first step of this capturing process, the PS remains intact with its ringlike structure, while the distance between the PS and the $\mathrm{C}_{\mathrm{uc}}$ reduces from 5.8 to $3.4 \AA$. At a certain distance, the $\mathrm{S}$ atom closest to the $\mathrm{C}_{\mathrm{uc}}$ has one of its $\mathrm{S}-\mathrm{S}$ bonds broken; in this case, we observe a fragmentation that creates two polysulfides with three $S$ atoms on each chain. While one of the PS chains is attached to the polymer, the other is kept by the $\mathrm{Li}$ atom shared between the two chains. With time, one of the $\mathrm{Li}$ atoms moves to the $\mathrm{N}$ atoms of the polymer, interacting electrostatically with one PS fragment. The other Li stays between both PS fragments, of which one is connected to the $C_{u c}$, while the other dissolves into the electrolyte. Subsequently, the bound PS detaches, resulting in Li being solely solvated by $\mathrm{N}$ atoms of the c-PAN and oxygen atoms from solvent molecules. This allows the attached PS fragment to reconnect to the other PS chain, forming a ringlike structure attached to the system. Finally, the PS elongates, assuming the same structure as in the system with the initially attached PS (Figure 1B). The total energy change during the capturing process by a $\mathrm{C}_{\mathrm{uc}}$ site is around $-4.4 \mathrm{eV}$, which can be divided into different steps. The capturing and fragmentation of the PS into the $\mathrm{C}_{\mathrm{uc}}$ is around $-1.2 \mathrm{eV}$, producing two $\mathrm{S}_{3}$ fragments. The removal of $\mathrm{Li}$ ions from the PS to c-PAN is around $-1.6 \mathrm{eV}$, the fragments recombination is around $-1.1 \mathrm{eV}$, and the PS reconfiguration is around $-0.5 \mathrm{eV}$. Several intermediary steps are shown in Figure 2. $\mathrm{C}_{\mathrm{uc}}$ can capture PS from the electrolyte, but the process may also create smaller PS fragments, whose sulfur chains recombine to produce longer chains. The simulations indicate that $\mathrm{C}_{\mathrm{uc}}$ tends to capture the closest $S$ atom from the PS, which results in fragmentation and recombination of the PS. Rotation of the PS was not observed setting the PS at 5.8 $\AA$, but the PS should also be captured by the chain edge without producing fragmentation and recombination.

When both LiTFSI and PS are present in the electrolyte and not connected to the polymer, the PS is also attracted by the $\mathrm{C}_{\mathrm{uc}}$ site, leading now to a fragmentation that produces $\mathrm{S}_{2}$ as well as $\mathrm{S}_{4}$ (Figure S2). Without the presence of c-PAN, the fragmentation of the PS is not thermodynamically favorable ${ }^{63}$ but becomes favorable in the presence of c-PAN containing a $\mathrm{C}_{\mathrm{uc}}$. The energy change caused by the interaction between the PS and the $C_{u c}$ site as well as the following fragmentation process is around $-2.8 \mathrm{eV}$ and therefore more favorable than the previous case, in which the PS fragments break into two $S_{3}$ units $(-1.2 \mathrm{eV}$ vs $-2.8 \mathrm{eV})$. This behavior is different from another model where no LiTFSI was present in the system and where the $S_{6}$ chain was chemically bound to the polymer. In other words, the capturing mechanism can occur in different ways. In the presence of LiTFSI, the salt removes Li from the PS, leading to two solvated $\mathrm{Li}$ atoms in the salt. In the abovementioned cases, Li that initially originated from the PS is completely removed by the polymer. However, in the presence of LiTFSI, the $\mathrm{Li}$ atom that is solvated by the polymer and by PS is not completely removed from the PS during the simulation time. In the simulations where the salt is not present in the electrolyte, $\mathrm{Li}$ absorbs into the polymer backbone and, after a certain period of time, this Li does not coordinate with the PS anymore. Additionally, the final fragments are maintained separated from each other, indicating that the salt can affect the interactions between PS and the polymer. In fact, this indicates that the salt deaccelerates the sulfur chain recombination and the $\mathrm{Li}$ capturing by the backbone.

When the electrolyte is composed of DOL and LiTFSI, but LiTFSI is still too far (7.9 $\AA$ ) from the polymer to interact with the $\mathrm{C}_{\mathrm{uc}}$ site, the solvent molecules react with the undercoordinated carbon $\mathrm{C}_{\mathrm{uc}}$ (see Figure 3). In the first step, an $\mathrm{O}$ atom from a DOL molecule binds to the $\mathrm{C}_{\mathrm{uc}}$ at the backbone $(\sim 0.8 \mathrm{eV})$; the overcoordination of $\mathrm{O}$ atoms from DOL leads to $\mathrm{C}-\mathrm{O}$ bond cleavage that finally produces $\mathrm{OCH}_{2} \mathrm{CH}_{2} \mathrm{OCH}_{2}$ with $\mathrm{O}$ being connected to the $\mathrm{C}$ atom from the $\mathrm{C}_{\mathrm{uc}}$ of the polymer. The total energy change in the decomposition mechanism of DOL is around $2.3 \mathrm{eV}$. The simulations suggest that PS will be captured in preference to the solvent decomposition $(-4.4 \mathrm{eV}$ vs $-2.3 \mathrm{eV})$. This is an indication that if a $\mathrm{C}_{\mathrm{uc}}$ is formed at the polymer, the $\mathrm{C}_{\mathrm{uc}}$ will promote solvent decomposition. This might lead to further reactions that require additional analyses and simulations. Regarding the LiTFSI salt, the simulation indicates that it does not tend to react with the $\mathrm{C}_{\mathrm{uc}}$ of the polymer, since in our simulations even when the salt is placed close $\left(3.1 \AA\right.$ ) to the $\mathrm{C}_{\mathrm{uc}}$ (see Figure S3), 

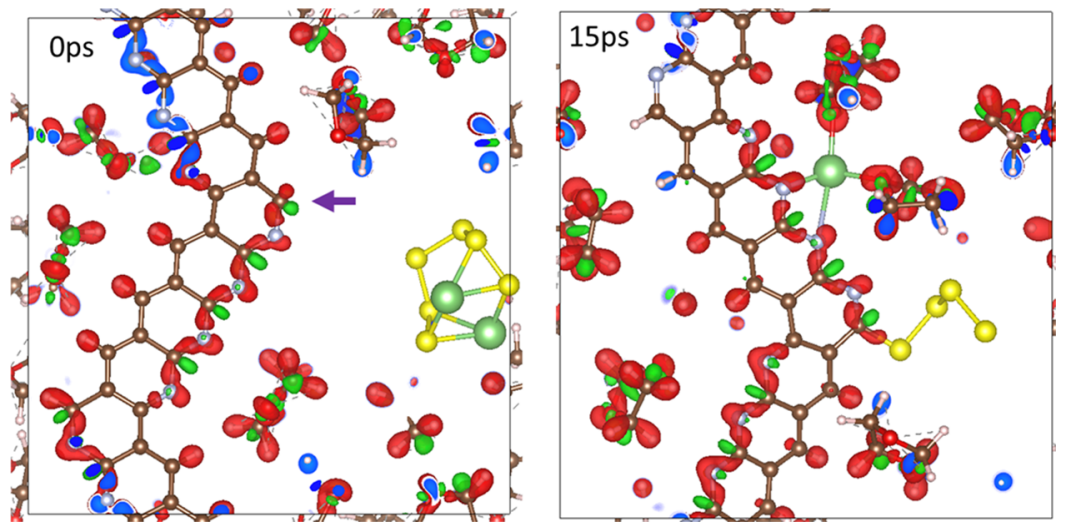

Figure 4. Charge difference isosurface of the interaction between c-PAN and PS. The isosurface has a cutoff of $0.3 \mathrm{e}$, where red is an accumulation of electrons (negative charge) and green is a depletion of electrons (positive charge). The blue color represents a cleavage in the isosurface produced by the visual plan cleavage. The purple arrow indicates the position of the $\mathrm{C}_{\mathrm{uc}}$. For simplicity of the model and image, a slide of the cell is visualized with the atoms and isosurface, while the other regions of the cell are hidden. Color coding: $\mathrm{C}$ is brown, $\mathrm{N}$ is cyan, $\mathrm{H}$ is white, $\mathrm{O}$ is red, and $S$ is yellow.

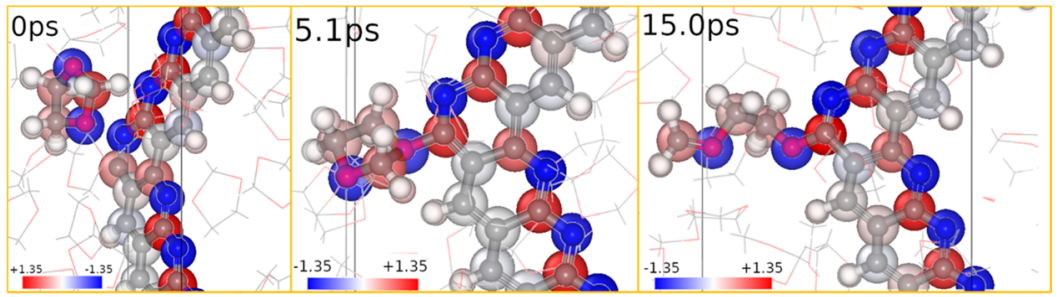

Figure 5. Atom charge distribution of the system as described in Figure 3. The color code is described in Figure 1; however, the atoms are displayed in a translucid way overlapping the charged spheres. The charged sphere is colored accordingly with the scale in this figure.

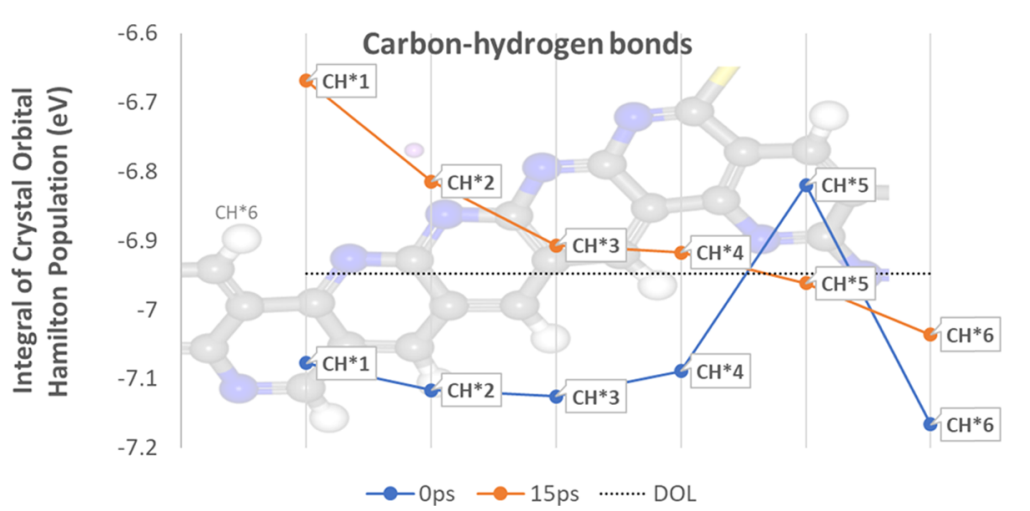

Figure 6. Integral of the Crystal Orbital Hamilton Population of $\mathrm{C}-\mathrm{H}$ bonds that belong to the system represented in Figure $1 \mathrm{~A}$. $\mathrm{CH}^{* \#}$ is numbered according to the position of each $\mathrm{C}-\mathrm{H}$ bond, where \# is an integer number.

the salt molecule moves away from the polymer backbone, assuming a configuration similar to the one shown in Figure 1B. The solvent indicates to play an important role by removing the available $\mathrm{C}_{\mathrm{uc}}$ mainly during the first cycles before the dissolution of PSs. Therefore, changing the solvent has the potential to improve cyclability. However, it cannot be considered conclusive that DOL will always react with $\mathrm{C}_{\mathrm{uc}}$ because c-PAN can capture $\mathrm{Li}$ ions from the PS and change its charge. The decomposition mechanism of DOL in a charged cPAN should be further investigated to elucidate this mechanism.

To illuminate the interactions and processes of capturing a PS by the c-PAN, we investigated changes in the charge density distribution around the $\mathrm{C}_{\mathrm{uc}}$ site of c-PAN and after capturing the PS (see Figure 4). In the c-PAN backbone, $\mathrm{H}$ atoms are surrounded by a negative charge (accumulation of electrons); however, $\mathrm{H}$ itself tends to have a slightly positive average total charge of $\sim 0.10 e$. The $\mathrm{N}$ atoms have an average charge of $-1.20 e$, while carbon atoms bound to $\mathrm{N}$ atoms tend to have a charge of $1.05 e$. The negative charge also concentrates on the lone-pair orbital of the $\mathrm{N}$ atoms and between $\mathrm{C}-\mathrm{N}$ bonds, while the positive charge (electron depletion) accumulates on the lone-pair region of $\mathrm{C}$ atoms. Moreover, Li prefers staying between two nitrogen lone pairs. The charge of the $\mathrm{C}$ atom that forms the $\mathrm{C}_{\mathrm{uc}}$ site changes slightly from 0.55 to $0.65 e$ after binding the PS. During the first 15 ps of the simulation, the total charge of the c-PAN changes from being neutral to $-0.92 e$, while the PS changes from -1.61 to -0.71 e. Consequently, our simulations indicated that the PS transfers electrons to the c-PAN when bound to an 
undercoordinated carbon (i.e., $\mathrm{C}_{\mathrm{uc}}$ ) and that the polymer might also act as an active material in a battery by accumulating $\mathrm{Li}$ ions. Moreover, in the PS, the charge decays from the beginning of the chain, where the $S$ atom is attached to the polymer, toward the $\mathrm{S}$ atom that holds the $\mathrm{Li}$ ion, finally becoming more negative on the edge of the chain. The isosurface charges indicate that the $\mathrm{PS}$ and $\mathrm{Li}$ ions were captured by the lone pair of $\mathrm{C}_{\mathrm{uc}}$ and $\mathrm{N}$ atoms, respectively.

When the electrolyte decomposes prior to binding to the $\mathrm{C}_{\mathrm{uc}}$ site, there is a more pronounced change in the charge at the undercoordinated carbon as well as the carbon of the DOL $\left(-\mathrm{CH}_{2}-\right)$ that breaks its bond with $\mathrm{O}$ (as shown in Figure 5). The $\mathrm{C}_{\mathrm{uc}}$ changes its charge from 0.45 to $1.30 e$, while the latter carbon atom from the electrolyte $\left(-\mathrm{CH}_{2}-\right)$ reduces its charge from 0.86 to $0.43 e$. Different from the previous case, in both structures, the decomposed DOL and the polymer remain neutral. Thus, although the polymer $\mathrm{C}_{\mathrm{uc}}$ leads to solvent decomposition, there is no net charge transfer occurring between the reactants as observed with the capturing of a PS.

The integral of the COHP for $\mathrm{C}-\mathrm{H}$ bonds that belong to $\mathrm{c}$ PAN is shown in Figure 6. It indicates an increase of the COHP energy after adsorption of the PS by the $\mathrm{C}_{\mathrm{uc}}$. In general, the more negative the COHP energies are, the stronger is the bond between the two atoms. Consequently, once the PS is captured by the $\mathrm{C}_{\mathrm{uc}}$ and $\mathrm{Li}$ is removed from the PS to the backbone, the $\mathrm{C}-\mathrm{H}$ bonds become weaker, changing from around $-7.07 \mathrm{eV}$ to around $-6.88 \mathrm{eV}$. The weakest bonds in the c-PAN tend to be localized close to where the $\mathrm{Li}$ ion was adsorbed on the polymer $\left(\mathrm{CH}^{*} 1, \mathrm{CH}^{*} 2\right.$, and $\mathrm{CH}^{*} 3$ in Figure $6)$. This may be associated with the excess of electrons in the polymer backbone after absorption of the PS. The average integral of the COHP for $\mathrm{C}-\mathrm{H}$ that belongs to the DOL has an average value of $-6.94 \mathrm{eV}$, which tends to be lower than the $\mathrm{C}-\mathrm{H}$ bonds from c-PAN after having captured the PS $(\sim 6.88$ $\mathrm{eV}$ ). In other words, DOL tends to be more stable and c-PAN less stable against the removal of hydrogen after adsorption of PS. Therefore, in a competition to remove $\mathrm{H}$ atoms from the solvent or the polymer, the absorption of PS and Li in the PAN may affect the species that should react.

As for the cathode materials, where $\mathrm{H}$ atoms from the solvent can be removed by salt species, ${ }^{47-50}$ the same may happen to c-PAN during cycling, creating new $\mathrm{C}_{\mathrm{uc}}$ units. Nevertheless, some DOL molecules have lower COHP energies than the $\mathrm{C}-\mathrm{H}$ bonds of c-PAN. The smallest COHP for DOL and c-PAN were 6.43 and $6.67 \mathrm{eV}$, respectively. This may lead to the decomposition of the solvent, instead of the creation of new $\mathrm{C}_{\mathrm{uc}}$ sites. Moreover, since the reactions may involve depletion of electrons, it is necessary to investigate whether the c-PAN becomes more or less stable during such an electron depletion process.

The previously decomposed solvent molecules (e.g. as shown in Figure 3) might also trigger removal of $\mathrm{H}$ from $\mathrm{c}$ PAN or supply $\mathrm{H}$ for the sulfur atoms in the SPAN. Further analyses should be done to better understand the behavior of c-PAN under such conditions. Here, our calculations indicate that the stability of the $\mathrm{C}-\mathrm{H}$ bonds in c-PAN should change during cycling of the LiSB. Assuming that the minimum $\mathrm{COHP}(\mathrm{C}-\mathrm{H})$ value is more relevant than the overall average value, other solvents with stronger $\mathrm{C}-\mathrm{H}$ bonds could be used instead of DOL to activate the generation of $\mathrm{C}_{\mathrm{uc}}$ during the LiSB cycling instead of decomposing the solvent (when salts such as $\mathrm{LiBr}$ are used in the electrolyte).
We also calculated the bond strength of PS as a fragment (observed after $0.76 \mathrm{ps}$ ) and after recombination of the S-S bond (observed after $15 \mathrm{ps}$ ), as shown in Figure 2. The results summarized in Figure S4 suggest that in the fragmented structure, the bond strength of both $\mathrm{S}-\mathrm{Li}$ and $\mathrm{S}-\mathrm{S}$ bonds is higher compared to that of the recombined case. The COHP of the sulfur fragment varies from an average of -6.90 to -5.56 $\mathrm{eV}$, and the COHP of every $\mathrm{S}-\mathrm{Li}$ bond changes from -0.77 to $-0.27 \mathrm{eV}$, on comparing simulation snapshots at 0.76 and 15.0 ps, respectively. Nevertheless, S-Li bonds are typically weaker than $\mathrm{S}-\mathrm{S}$ bonds $(\sim 5.7 \mathrm{eV}$ vs $0.6 \mathrm{eV})$; the covalent and ionic effect on COHP can also be observed in the literature for $\mathrm{Na}-$ $\mathrm{S}, \mathrm{Li}-\mathrm{O}$, and $\mathrm{S}-\mathrm{S} .^{97-99}$ Therefore, it is expected that fragments might recombine as a whole, without encountering further cleavage of the sulfur chains, which agrees with our simulations.

\section{CONCLUSIONS}

In the present work, we have studied the capturing process of a PS by a $\mathrm{C}_{\mathrm{uc}}$ in the c-PAN backbone, the reactions between this $\mathrm{C}_{\mathrm{uc}}$ and the solvent, and the effect of the salt in the PScapturing process. We considered undercoordinated carbon $\left(\mathrm{C}_{\mathrm{uc}}\right)$ that was formed by three different processes:

- during the syntheses, where $\mathrm{H}$ is removed from the backbone by sulfur, without binding a sulfur chain to $\mathrm{C}_{\mathrm{uc}}$;

- by removal of sulfur from carbon during battery cycling; and

- by removal of hydrogen from the backbone due to its reaction with a nearby salt molecule.

Our simulations indicate that c-PAN is capable of catching a PS chain dissolved in the electrolyte and of removing $\mathrm{Li}$ from this PS when $\mathrm{C}_{\mathrm{uc}}$ is available at the polymer backbone. In other words, when a carbon atom at the c-PAN structure is missing its $\mathrm{H}$ termination, this carbon can bind to the sulfur-chain of a PS. During this capturing process, some $S-S$ bonds might break, forming temporary fragments attached to the adsorbed PS. Afterward, these PS might recombine, forming S-S bonds, while the PS will assume a linear configuration with only one $\mathrm{Li}$-ion being attached to the edge of the PS, and the other $\mathrm{Li}$ ion being adsorbed at $\mathrm{N}$ sites of the polymer. Consequently, cPAN might also act as an active material in the battery. The PS takes a similar configuration when the PS is initially attached to the polymer or when being solvated in the electrolyte. However, the salt seems to influence the lifetime of the PS fragments, increasing the time required for fragment recombination and leading to the formation of longer chains. Moreover, the PS shows a tendency to weaken the bond between hydrogen and the backbone. The mechanism in which the $\mathrm{C}_{\mathrm{uc}}$ captures the PSs may change accordingly with the initial configuration of the PS. However, the recombination of S-S chains suggests that the attached PS will commonly assume a linear configuration with one $\mathrm{Li}$ ion on the edge of the sulfur chain.

These $\mathrm{C}_{\mathrm{uc}}$ sites are also able to react with the solvent, breaking a $\mathrm{C}-\mathrm{O}$ bond (from carbon on $-\mathrm{CH}_{2}-$ ) and creating a new branch in the c-PAN polymeric structure. Further research may investigate if PS can absorb on the decomposed DOL ramification, bounded by the c-PAN or further reactions can occur in that ramification. Also, more investigation should be conducted to investigate whether salt species (such as $\mathrm{LiBr}$ ) are capable to generate additional $\mathrm{C}_{\mathrm{uc}}$ units. The absorption of 
PS leads to weaker $\mathrm{C}-\mathrm{H}$ bonds in the c-PAN, when closer to the attached PS. However, c-PAN has on average weaker $\mathrm{C}-\mathrm{H}$ bonds than DOL, while the solvent has the weakest $\mathrm{C}-\mathrm{H}$ bonds.

We can conclude that c-PAN might also act as an active material, not only by allowing lithiation of sulfur but also by capturing $\mathrm{Li}$ ions. The polymer backbone can capture PS from the electrolyte, producing PS fragments. These PS fragments might recombine to form long-chain PSs. However, in the presence of the salt, this recombination process is deaccelerated. Finally, the strength of $\mathrm{C}-\mathrm{H}$ bonds decreases with the degree of lithiation of the polymer.

\section{ASSOCIATED CONTENT}

\section{SI Supporting Information}

The Supporting Information is available free of charge at https://pubs.acs.org/doi/10.1021/acsomega.0c06240.

Complementary AIMD figures mentioned above and the COHP analyses of S-S and S-Li (PDF)

\section{AUTHOR INFORMATION}

\section{Corresponding Author}

Timo Jacob - Institute of Electrochemistry, Ulm University, 89081 Ulm, Germany; Helmholtz-Institute Ulm (HIU) Electrochemical Energy Storage, 89081 Ulm, Germany; Karlsruhe Institute of Technology (KIT), 76021 Karlsruhe, Germany; (1) orcid.org/0000-0001-7777-2306;

Email: timo.jacob@uni-ulm.de

\section{Author}

Samuel Bertolini - Institute of Electrochemistry, Ulm University, 89081 Ulm, Germany; 이이.org/0000-00030969-7142

Complete contact information is available at:

https://pubs.acs.org/10.1021/acsomega.0c06240

\section{Notes}

The authors declare no competing financial interest.

\section{ACKNOWLEDGMENTS}

Support from the Deutsche Forschungsgemeinschaft (DFG) through Project ID 390874152 (POLiS Cluster of Excellence) as well as the Schwerpunktprogramm (priority program) SPP2248 (polymer-based batteries) is gratefully acknowledged. The authors also acknowledge the computer time supported by the state of Baden-Württemberg through the HPC project and the DFG through Grant Number INST40/467-1 FUGG.

\section{REFERENCES}

(1) Zhou, L. Progress and problems in hydrogen storage methods. Renewable Sustainable Energy Rev. 2005, 9, 395-408.

(2) Tachan, Z.; Rühle, S.; Zaban, A. Dye-sensitized solar tubes: A new solar cell design for efficient current collection and improved cell sealing. Sol. Energy Mater. Sol. Cells 2010, 94, 317-322.

(3) Lu, L.; Yang, H.; Burnett, J. Investigation on wind power potential on Hong Kong islands - an analysis of wind power and wind turbine characteristics. Renewable Energy 2002, 27, 1-12.

(4) Burke, A. F. Batteries and ultracapacitors for electric, hybrid, and fuel cell vehicles. Proc. IEEE 2007, 95, 806-820.

(5) Zarnikau, J. Consumer demand for 'green power'and energy efficiency. Energy Policy 2003, 31, 1661-1672.

(6) Rowlands, I. H.; Parker, P.; Scott, D. Consumer perceptions of "green power". J. Consum. Mark. 2002, 19, 112-129.
(7) Thackeray, M. M.; Wolverton, C.; Isaacs, E. D. Electrical energy storage for transportation-approaching the limits of, and going beyond, lithium-ion batteries. Energy Environ. Sci. 2012, 5, 78547863.

(8) Bruce, P. G.; Hardwick, L. J.; Abraham, K. M. Lithium-air and lithium-sulfur batteries. MRS Bull. 2011, 36, 506-512.

(9) Wadia, C.; Albertus, P.; Srinivasan, V. Resource constraints on the battery energy storage potential for grid and transportation applications. J. Power Sources 2011, 196, 1593-1598.

(10) Bruce, P. G.; Freunberger, S. A.; Hardwick, L. J.; Tarascon, J.M. $\mathrm{Li}^{-} \mathrm{O}_{2}$ and $\mathrm{Li}-\mathrm{S}$ batteries with high energy storage. Nat. Mater. 2012, 11, 19-29.

(11) Chen, L.; Shaw, L. L. Recent advances in lithium-sulfur batteries. J. Power Sources 2014, 267, 770-783.

(12) Son, Y.; Lee, J. S.; Son, Y.; Jang, J. H.; Cho, J. Recent Advances in Lithium Sulfide Cathode Materials and Their Use in Lithium Sulfur Batteries. Adv. Energy Mater. 2015, 5, No. 1500110.

(13) Ji, X.; Nazar, L. F. Advances in Li-S batteries. J. Mater. Chem. 2010, 20, 9821-9826.

(14) Yuan, L.; Qiu, X.; Chen, L.; Zhu, W. New insight into the discharge process of sulfur cathode by electrochemical impedance spectroscopy. J. Power Sources 2009, 189, 127-132.

(15) Barchasz, C.; Leprêtre, J.-C.; Alloin, F.; Patoux, S. New insights into the limiting parameters of the $\mathrm{Li} / \mathrm{S}$ rechargeable cell. J. Power Sources 2012, 199, 322-330.

(16) Yang, Y.; Zheng, G.; Misra, S.; Nelson, J.; Toney, M. F.; Cui, Y. High-capacity micrometer-sized $\mathrm{Li}_{2} \mathrm{~S}$ particles as cathode materials for advanced rechargeable lithium-ion batteries. J. Am. Chem. Soc. 2012, 134, 15387-15394.

(17) Chen, Y.-X.; Kaghazchi, P. Metalization of $\mathrm{Li}_{2} \mathrm{~S}$ particle surfaces in Li-S batteries. Nanoscale 2014, 6, 13391-13395.

(18) Yang, Y.; Zheng, G.; Cui, Y. Nanostructured sulfur cathodes. Chem. Soc. Rev. 2013, 42, 3018-3032.

(19) Schneider, H.; Gollub, C.; Weiss, T.; Kulisch, J.; Leitner, K.; Schmidt, R.; Safont-Sempere, M. M.; Mikhaylik, Y.; Kelley, T.; Scordilis-Kelley, C.; Laramie, M.; Du, H. On the Electrode Potentials in Lithium-Sulfur Batteries and Their Solvent-Dependence. J. Electrochem. Soc. 2014, 161, A1399-A1406.

(20) Hofmann, A. F.; Fronczek, D. N.; Bessler, W. G. Mechanistic modeling of polysulfide shuttle and capacity loss in lithium-sulfur batteries. J. Power Sources 2014, 259, 300-310.

(21) Yang, Y.; Yu, G.; Cha, J. J.; Wu, H.; Vosgueritchian, M.; Yao, Y.; Bao, Z.; Cui, Y. Improving the performance of lithium-sulfur batteries by conductive polymer coating. ACS Nano 2011, 5, 91879193.

(22) Li, W.; Zheng, G.; Yang, Y.; Seh, Z. W.; Liu, N.; Cui, Y. Highperformance hollow sulfur nanostructured battery cathode through a scalable, room temperature, one-step, bottom-up approach. Proc. Natl. Acad. Sci. U.S.A. 2013, 110, 7148-7153.

(23) Zhang, B.; Qin, X.; Li, G.; Gao, X. Enhancement of long stability of sulfur cathode by encapsulating sulfur into micropores of carbon spheres. Energy Environ. Sci. 2010, 3, 1531-1537.

(24) Li, X.; Cao, Y.; Qi, W.; Saraf, L. V.; Xiao, J.; Nie, Z.; Mietek, J.; Zhang, J.-G.; Schwenzer, B.; Liu, J. Optimization of mesoporous carbon structures for lithium-sulfur battery applications. J. Mater. Chem. 2011, 21, 16603-16610.

(25) Liang, C.; Dudney, N. J.; Howe, J. Y. Hierarchically structured sulfur/carbon nanocomposite material for high-energy lithium battery. Chem. Mater. 2009, 21, 4724-4730.

(26) Zheng, W.; Liu, Y.; Hu, X.; Zhang, C. Novel nanosized adsorbing sulfur composite cathode materials for the advanced secondary lithium batteries. Electrochim. Acta 2006, 51, 1330-1335.

(27) Su, Y.-S.; Fu, Y.; Manthiram, A. Self-weaving sulfur-carbon composite cathodes for high rate lithium-sulfur batteries. Phys. Chem. Chem. Phys. 2012, 14, 14495-14499.

(28) Manthiram, A.; Su, Y.-S. Binder-Free Sulfur-Carbon Nanotube Composite Cathodes for Rechargeable Lithium-Sulfur Batteries and Methods of Making the Same. WI2013096751A12015. 
(29) Zheng, G.; Yang, Y.; Cha, J. J.; Hong, S. S.; Cui, Y. Hollow carbon nanofiber-encapsulated sulfur cathodes for high specific capacity rechargeable lithium batteries. Nano Lett. 2011, 11, 44624467.

(30) Ji, L.; Rao, M.; Aloni, S.; Wang, L.; Cairns, E. J.; Zhang, Y. Porous carbon nanofiber-sulfur composite electrodes for lithium/ sulfur cells. Energy Environ. Sci. 2011, 4, 5053-5059.

(31) Guo, J.; Xu, Y.; Wang, C. Sulfur-impregnated disordered carbon nanotubes cathode for lithium-sulfur batteries. Nano Lett. 2011, 11, $4288-4294$

(32) Ye, H.; Yin, Y.-X.; Xin, S.; Guo, Y.-G. Tuning the porous structure of carbon hosts for loading sulfur toward long lifespan cathode materials for Li-S batteries. J. Mater. Chem. A 2013, 1, 6602-6608

(33) Tao, X.; Chen, X.; Xia, Y.; Huang, H.; Gan, Y.; Wu, R.; Chen, F.; et al. Highly mesoporous carbon foams synthesized by a facile, cost-effective and template-free Pechini method for advanced lithium-sulfur batteries. J. Mater. Chem. A 2013, 1, 3295-3301.

(34) Wei, S.; Zhang, H.; Huang, Y.; Wang, W.; Xia, Y.; Yu, Z. Pig bone derived hierarchical porous carbon and its enhanced cycling performance of lithium-sulfur batteries. Energy Environ. Sci. 2011, 4, $736-740$.

(35) Zhang, B.; Lai, C.; Zhou, Z.; Gao, X. Preparation and electrochemical properties of sulfur-acetylene black composites as cathode materials. Electrochim. Acta 2009, 54, 3708-3713.

(36) Jayaprakash, N.; Shen, J.; Moganty, S. S.; Corona, A.; Archer, L. A. Porous hollow carbon @ sulfur composites for high-power lithium-sulfur batteries. Angew. Chem. 2011, 123, 6026-6030.

(37) Yuan, L.; Yuan, H.; Qiu, X.; Chen, L.; Zhu, W. Improvement of cycle property of sulfur-coated multi-walled carbon nanotubes composite cathode for lithium/sulfur batteries. J. Power Sources 2009, 189, 1141-1146.

(38) Song, M.-S.; Han, S.-C.; Kim, H.-S.; Kim, J.-H.; Kim, K.-T.; Kang, Y.-M.; Ahn, H.-J.; Dou, S.; Lee, J.-Y. Effects of nanosized adsorbing material on electrochemical properties of sulfur cathodes for Li/S secondary batteries. J. Electrochem. Soc. 2004, 151, A791A795.

(39) Zhang, Y.; Zhao, Y.; Yermukhambetova, A.; Bakenov, Z.; Chen, $\mathrm{P}$. Ternary sulfur/polyacrylonitrile/Mg0.6Ni0.4O composite cathodes for high performance lithium/sulfur batteries. J. Mater. Chem. A 2013, $1,295-301$.

(40) Choi, Y.; Jung, B.; Lee, D.; Jeong, J.; Kim, K.; Ahn, H.; Cho, K.; $\mathrm{Gu}, \mathrm{H}$. Electrochemical properties of sulfur electrode containing nano $\mathrm{Al}_{2} \mathrm{O}_{3}$ for lithium/sulfur cell. Phys. Scr. 2007, 2007, No. 62.

(41) Ji, X.; Evers, S.; Black, R.; Nazar, L. F. Stabilizing lithiumsulphur cathodes using polysulphide reservoirs. Nat. Commun. 2011, 2, No. 325.

(42) Evers, S.; Yim, T.; Nazar, L. F. Understanding the nature of absorption/adsorption in nanoporous polysulfide sorbents for the $\mathrm{Li}-$ S battery. J. Phys. Chem. C 2012, 116, 19653-19658.

(43) Song, J.; Gordin, M. L.; Xu, T.; Chen, S.; Yu, Z.; Sohn, H.; Lu, J.; Ren, Y.; Duan, Y.; Wang, D. Strong lithium polysulfide chemisorption on electroactive sites of nitrogen-doped carbon composites for high-performance lithium-sulfur battery cathodes. Angew. Chem. 2015, 127, 4399-4403.

(44) Han, K.; Shen, J.; Hao, S.; Ye, H.; Wolverton, C.; Kung, M. C.; Kung, H. H. Free-Standing Nitrogen-doped Graphene Paper as Electrodes for High-Performance Lithium/Dissolved Polysulfide Batteries. ChemSusChem 2014, 7, 2545-2553.

(45) Balach, J.; Jaumann, T.; Klose, M.; Oswald, S.; Eckert, J.; Giebeler, L. Improved cycling stability of lithium-sulfur batteries using a polypropylene-supported nitrogen-doped mesoporous carbon hybrid separator as polysulfide adsorbent. J. Power Sources 2016, 303, $317-324$

(46) Li, W.; Yao, H.; Yan, K.; Zheng, G.; Liang, Z.; Chiang, Y.-M.; Cui, Y. The synergetic effect of lithium polysulfide and lithium nitrate to prevent lithium dendrite growth. Nat. Commun. 2015, 6, No. 7436.

(47) Wu, F.; Thieme, S.; Ramanujapuram, A.; Zhao, E.; Weller, C.; Althues, H.; Kaskel, S.; Borodin, O.; Yushin, G. Toward in-situ protected sulfur cathodes by using lithium bromide and pre-charge. Nano Energy 2017, 40, 170-179.

(48) Borodin, O.; Behl, W.; Jow, T. R. Oxidative stability and initial decomposition reactions of carbonate, sulfone, and alkyl phosphatebased electrolytes. J. Phys. Chem. C 2013, 117, 8661-8682.

(49) Kim, H.; Wu, F.; Lee, J. T.; Nitta, N.; Lin, H. T.; Oschatz, M.; Cho, W. I.; Kaskel, S.; Borodin, O.; Yushin, G. In Situ Formation of Protective Coatings on Sulfur Cathodes in Lithium Batteries with LiFSI-Based Organic Electrolytes. Adv. Energy Mater. 2015, 5, No. 1401792

(50) Wu, F.; Lee, J. T.; Nitta, N.; Kim, H.; Borodin, O.; Yushin, G. Lithium iodide as a promising electrolyte additive for lithium-sulfur batteries: mechanisms of performance enhancement. Adv. Mater. 2015, 27, 101-108.

(51) Zhang, S.-c.; Zhang, L.; Wang, W.-k.; Xue, W.-j. A Novel cathode material based on polyaniline used for lithium/sulfur secondary battery. Synth. Met. 2010, 160, 2041-2044.

(52) Xiao, L.; Cao, Y.; Xiao, J.; Schwenzer, B.; Engelhard, M. H.; Saraf, L. V.; Nie, Z.; Exarhos, G. J.; Liu, J. A soft approach to encapsulate sulfur: polyaniline nanotubes for lithium-sulfur batteries with long cycle life. Adv. Mater. 2012, 24, 1176-1181.

(53) Wang, J.; Yang, J.; Xie, J.; Xu, N. A novel conductive polymersulfur composite cathode material for rechargeable lithium batteries. Adv. Mater. 2002, 14, 963-965.

(54) Zhang, Y.; Liu, S.; Li, G.; Li, G.; Gao, X. Sulfur/ polyacrylonitrile/carbon multi-composites as cathode materials for lithium/sulfur battery in the concentrated electrolyte. J. Mater. Chem. A 2014, 2, 4652-4659.

(55) Peng, H.; Wang, X.; Zhao, Y.; Tan, T.; Mentbayeva, A.; Bakenov, Z.; Zhang, Y. Enhanced electrochemical performance of sulfur/polyacrylonitrile composite by carbon coating for lithium/ sulfur batteries. J. Nanopart. Res. 2017, 19, No. 348.

(56) Li, J.; Li, K.; Li, M.; Gosselink, D.; Zhang, Y.; Chen, P. A sulfur-polyacrylonitrile/graphene composite cathode for lithium batteries with excellent cyclability. J. Power Sources 2014, 252, 107112.

(57) Fanous, J.; Wegner, M.; Grimminger, J.; Andresen, A.; Buchmeiser, M. R. Structure-related electrochemistry of sulfur-poly (acrylonitrile) composite cathode materials for rechargeable lithium batteries. Chem. Mater. 2011, 23, 5024-5028.

(58) Zhu, T.; Mueller, J. E.; Hanauer, M.; Sauter, U.; Jacob, T. Structural Motifs for Modeling Sulfur-Poly (acrylonitrile) Composite Materials in Sulfur-Lithium Batteries. ChemElectroChem 2017, 4, 2494-2499.

(59) Zhu, T.; Mueller, J. E.; Hanauer, M.; Sauter, U.; Jacob, T. Theoretical Studies on the Charging and Discharging of Poly (acrylonitrile)-Based Lithium-Sulfur Batteries. ChemElectroChem 2017, 4, 2975-2980.

(60) Frey, M.; Zenn, R. K.; Warneke, S.; Müller, K.; Hintennach, A.; Dinnebier, R. E.; Buchmeiser, M. R. Easily accessible, textile fiberbased sulfurized poly (acrylonitrile) as $\mathrm{Li} / \mathrm{S}$ cathode material: correlating electrochemical performance with morphology and structure. ACS Energy Lett. 2017, 2, 595-604.

(61) Doan, T. N. L.; Ghaznavi, M.; Zhao, Y.; Zhang, Y.; Konarov, A.; Sadhu, M.; Tangirala, R.; Chen, P. Binding mechanism of sulfur and dehydrogenated polyacrylonitrile in sulfur/polymer composite cathode. J. Power Sources 2013, 241, 61-69.

(62) Wei, S.; Ma, L.; Hendrickson, K. E.; Tu, Z.; Archer, L. A. Metal-sulfur battery cathodes based on PAN-sulfur composites. J. Am. Chem. Soc. 2015, 137, 12143-12152.

(63) Camacho-Forero, L. E.; Smith, T. W.; Bertolini, S.; Balbuena, P. B. Reactivity at the lithium-metal anode surface of lithium-sulfur batteries. J. Phys. Chem. C 2015, 119, 26828-26839.

(64) Liu, Z.; Bertolini, S.; Balbuena, P. B.; Mukherjee, P. P. Li 2 S film formation on lithium anode surface of $\mathrm{Li}-\mathrm{S}$ batteries. ACS Appl. Mater. Interfaces 2016, 8, 4700-4708.

(65) Bertolini, S.; Balbuena, P. B. Buildup of the solid electrolyte interphase on lithium-metal anodes: reactive molecular dynamics study. J. Phys. Chem. C 2018, 122, 10783-10791. 
(66) Beltran, S. P.; Balbuena, P. B. Formation of Multilayer Graphene Domains with Strong Sulfur-Carbon Interaction and Enhanced Sulfur Reduction Zones for Lithium-Sulfur Battery Cathodes. ChemSusChem 2018, 11, 1970-1980.

(67) Beltran, S. P.; Balbuena, P. B. First-principles explorations of the electrochemical lithiation dynamics of a multilayer graphene nanosheet-based sulfur-carbon composite. J. Mater. Chem. A 2018, 6, 18084-18094.

(68) Kamphaus, E. P.; Balbuena, P. B. Long-chain polysulfide retention at the cathode of $\mathrm{Li}-\mathrm{S}$ batteries. J. Phys. Chem. C 2016, 120, 4296-4305.

(69) Tao, X.; Wang, J.; Liu, C.; Wang, H.; Yao, H.; Zheng, G.; Seh, Z. W.; Cai, Q.; Li, W.; Zhou, G.; et al. Balancing surface adsorption and diffusion of lithium-polysulfides on nonconductive oxides for lithium-sulfur battery design. Nat. Commun. 2016, 7, No. 11203.

(70) Wang, L.; Zhang, T.; Yang, S.; Cheng, F.; Liang, J.; Chen, J. A quantum-chemical study on the discharge reaction mechanism of lithium-sulfur batteries. J. Energy Chem. 2013, 22, 72-77.

(71) Ma, Y. Computer simulation of cathode materials for lithium ion and lithium batteries: A review. Energy Environ. Mater. 2018, 1, $148-173$.

(72) Leung, K.; Soto, F.; Hankins, K.; Balbuena, P. B.; Harrison, K. L. Stability of solid electrolyte interphase components on lithium metal and reactive anode material surfaces. J. Phys. Chem. C 2016, 120, 6302-6313.

(73) Burgos, J. C.; Balbuena, P. B.; Montoya, J. A. Structural dependence of the sulfur reduction mechanism in carbon-based cathodes for lithium-sulfur batteries. J. Phys. Chem. C 2017, 121, 18369-18377.

(74) Wujcik, K. H.; Pascal, T. A.; Pemmaraju, C.; Devaux, D.; Stolte, W. C.; Balsara, N. P.; Prendergast, D. Characterization of Polysulfide Radicals Present in an Ether-Based Electrolyte of a Lithium-Sulfur Battery During Initial Discharge Using In Situ X-Ray Absorption Spectroscopy Experiments and First-Principles Calculations. Adv. Energy Mater. 2015, 5, No. 1500285.

(75) Kresse, G.; Hafner, J. Ab initio molecular dynamics for openshell transition metals. Phys. Rev. B 1993, 48, No. 13115.

(76) Kresse, G.; Furthmüller, J. Efficient iterative schemes for ab initio total-energy calculations using a plane-wave basis set. Phys. Rev. B 1996, 54, No. 11169.

(77) Car, R.; Parrinello, M. Unified Approach for MolecularDynamics and Density-Functional Theory. Phys. Rev. Lett. 1985, 55, No. 2471.

(78) Payne, M. C.; Teter, M. P.; Allan, D. C.; Arias, T. A.; Joannopoulos, J. D. Iterative minimization techniques for $\mathrm{ab}$ initio total-energy calculations: molecular dynamics and conjugate gradients. Rev. Mod. Phys. 1992, 64, No. 1045.

(79) Blöchl, P. E. Projector augmented-wave method. Phys. Rev. B 1994, 50, No. 17953.

(80) Kresse, G.; Joubert, D. From ultrasoft pseudopotentials to the projector augmented-wave method. Phys. Rev. B 1999, 59, No. 1758.

(81) Monkhorst, H. J.; Pack, J. D. Special Points for Brillouin-Zone Integrations. Phys. Rev. B 1976, 13, No. 5188.

(82) Nosé, S. A unified formulation of the constant temperature molecular dynamics methods. J. Chem. Phys. 1984, 81, 511-519.

(83) Nosé, S. Constant Temperature Molecular Dynamics Methods. Prog. Theor. Phys. Suppl. 1991, 103, 1-46.

(84) Bylander, D. M.; Kleinman, L. Energy fluctuations induced by the Nos`'e thermostat. Phys. Rev. B 1992, 46, No. 13756.

(85) Tang, W.; Sanville, E.; Henkelman, G. A grid-based Bader analysis algorithm without lattice bias. J. Phys.: Condens. Matter 2009, 21, No. 084204.

(86) Grimme, S.; Ehrlich, S.; Goerigk, L. Effect of the damping function in dispersion corrected density functional theory. J. Comput. Chem. 2011, 32, 1456-1465.

(87) Deringer, V. L.; Tchougréeff, A. L.; Dronskowski, R. Crystal orbital Hamilton population (COHP) analysis as projected from plane-wave basis sets. J. Phys. Chem. A 2011, 115, 5461-5466.
(88) Maintz, S.; Deringer, V. L.; Tchougréeff, A. L.; Dronskowski, R. LOBSTER: A tool to extract chemical bonding from plane-wave based DFT. J. Comput. Chem. 2016, 37, 1030-1035.

(89) Momma, K.; Izumi, F. VESTA: a three-dimensional visualization system for electronic and structural analysis. J. Appl. Crystallogr. 2008, 41, 653-658.

(90) Humphrey, W.; Dalke, A.; Schulten, K. VMD: visual molecular dynamics. J. Mol. Graphics 1996, 14, 33-38.

(91) Frisch, M. J.; Trucks, G. W.; Schlegel, H. B.; Scuseria, G. E.; Robb, M. A.; Cheeseman, J. R.; Scalmani, G.; Barone, V.; Mennucci, B.; Petersson, G. A.; Nakatsuji, H.; Caricato, M.; Li, X.; Hratchian, H. P.; Izmaylov, A. F.; Bloino, J.; Zheng, G.; Sonnenberg, J. L.; Hada, M.; Ehara, M.; Toyota, K.; Fukuda, R.; Hasegawa, J.; Ishida, M.; Nakajima, T.; Honda, Y.; Kitao, O.; Nakai, H.; Vreven, T.; Montgomery, J. A., Jr.; Peralta, J. E.; Ogliaro, Fo.; Bearpark, M. J.; Heyd, J.; Brothers, E. N.; Kudin, K. N.; Staroverov, V. N.; Kobayashi, R.; Normand, J.; Raghavachari, K.; Rendell, A. P.; Burant, J. C.; Iyengar, S. S.; Tomasi, J.; Cossi, M.; Rega, N.; Millam, N. J.; Klene, M.; Knox, J. E.; Cross, J. B.; Bakken, V.; Adamo, C.; Jaramillo, J.; Gomperts, R.; Stratmann, R. E.; Yazyev, O.; Austin, A. J.; Cammi, R.; Pomelli, C.; Ochterski, J. W.; Martin, R. L.; Morokuma, K.; Zakrzewski, V. G.; Voth, G. A.; Salvador, P.; Dannenberg, J. J.; Dapprich, S.; Daniels, A. D.; Farkas, Ã.; Foresman, J. B.; Ortiz, J. V.; Cioslowski, J.; Fox, D. J. Gaussian 09; Gaussian, Inc.: Wallingford, CT, 2009.

(92) Becke, A. D. Density-functional thermochemistry. III. The role of exact exchange. J. Chem. Phys. 1993, 98, 5648-5652.

(93) Perdew, J. P.; Chevary, J. A.; Vosko, S. H.; Jackson, K. A.; Pederson, M. R.; Singh, D. J.; Fiolhais, C. Atoms, molecules, solids, and surfaces: Applications of the generalized gradient approximation for exchange and correlation. Phys. Rev. B 1992, 46, No. 6671.

(94) Dauber-Osguthorpe, P.; Roberts, V. A.; Osguthorpe, D. J.; Wolff, J.; Genest, M.; Hagler, A. T. Structure and energetics of ligand binding to proteins: Escherichia coli dihydrofolate reductasetrimethoprim, a drug-receptor system. Proteins 1988, 4, 31-47.

(95) Ye, J.; He, F.; Nie, J.; Cao, Y.; Yang, H.; Ai, X. Sulfur/carbon nanocomposite-filled polyacrylonitrile nanofibers as a long life and high capacity cathode for lithium-sulfur batteries. J. Mater. Chem. A 2015, 3, 7406-7412.

(96) Wang, W.; Cao, Z.; Elia, G. A.; Wu, Y.; Wahyudi, W.; AbouHamad, E.; Emwas, A.-H.; Cavallo, L.; Li, L.-J.; Ming, J. Recognizing the mechanism of sulfurized polyacrylonitrile cathode materials for $\mathrm{Li}-\mathrm{S}$ batteries and beyond in $\mathrm{Al}-\mathrm{S}$ batteries. ACS Energy Lett. 2018, 3, 2899-2907.

(97) Olanrele, S. O.; Lian, Z.; Si, C.; Chen, S.; Li, B. Tuning of interactions between cathode and lithium polysulfide in Li-S battery by rational halogenation. J. Energy Chem. 2020, 49, 147-152.

(98) Wan, B.; Xu, S.; Yuan, X.; Tang, H.; Huang, D.; Zhou, W.; Wu, L.; Zhang, J.; Gou, H. Diversities of stoichiometry and electrical conductivity in sodium sulfides. J. Mater. Chem. A 2019, 7, 1647216478.

(99) Beltran, S. P.; Cao, X.; Zhang, J.-G.; Balbuena, P. B. Localized High Concentration Electrolytes for High Voltage Lithium-Metal Batteries: Correlation between the Electrolyte Composition and Its Reductive/Oxidative Stability. Chem. Mater. 2020, 32, 5973-5984. 